\title{
Sputnik Three Rocket Carrier Sighted
}

by Keith D. Baker, Weyburn

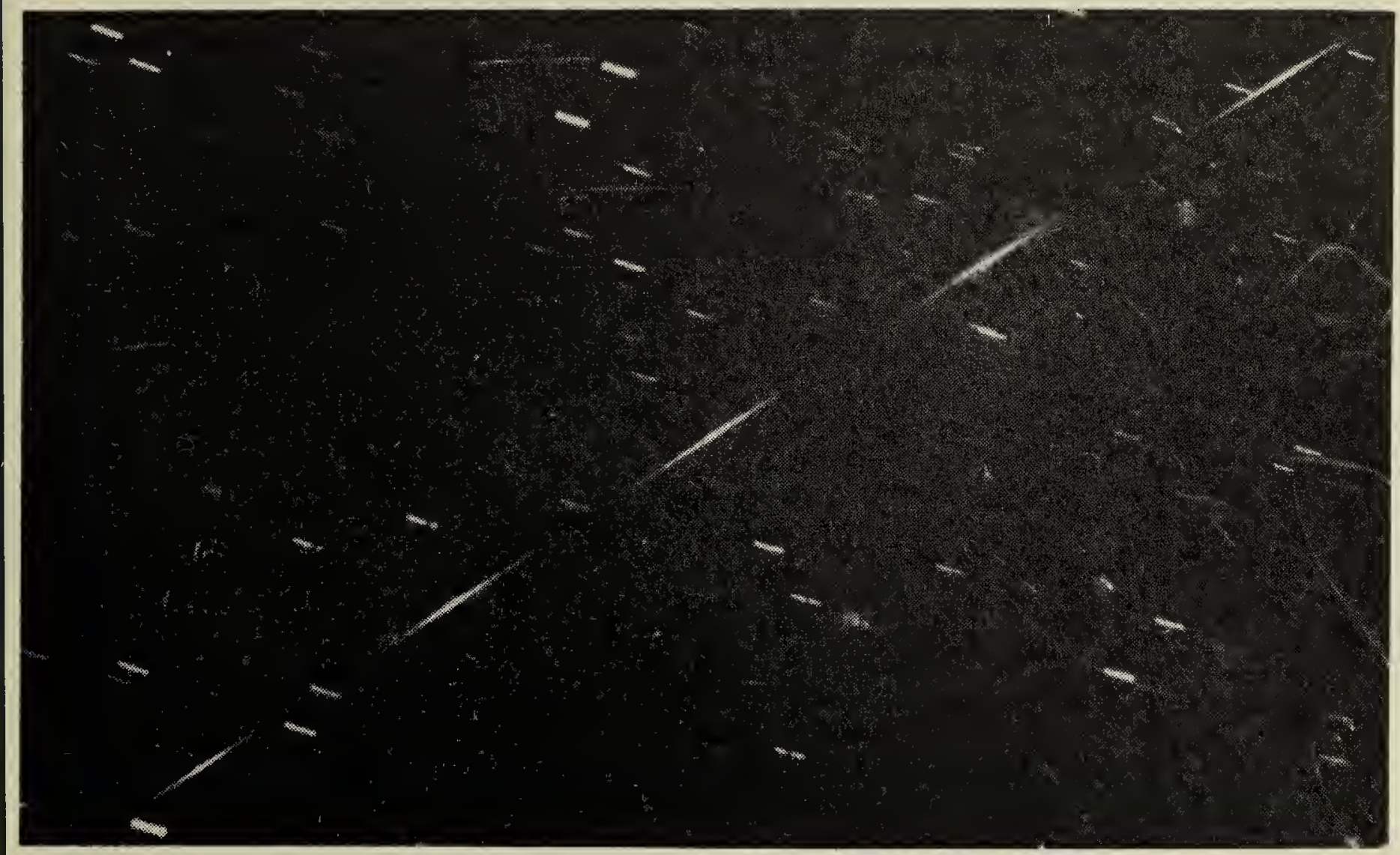

Photo by $K$. D. Baker

The above, 72 second, time exposure of the Sputnik III rocket carrier was taken at $\mathrm{f} 4.5$ on Kodak RoyalXPan sheet film, Graphic ' 23 ', on the night of August 12, 1958, at Weyburn. I was directing a meteor observation group here, under the direction and encouragement of John Hodges and the Regina Astronomical Society. We were fortunate enough to see the sputnik carrier several times and I was able to take the above photograph which was published by the Weyburn Review

The satellite carrier was seen August 12 for several minutes starting at 10.46 p.m.; August 13, 10.35 to 10.41 p.m. and again shortly after midnight; August 14, from 10.22 to 10.31 p.m.

The satellite carrier appeared as an intermittent pulsing light about 8 seconds on and 8 seconds off. The light on each pulse came on slowly, peaked to full brilliance and then gradually faded. The light could be seen again sooner if one was using binoculars and the light could be seen longer and the dark period was shorter when the carrier was directly overhead. The light is due to the sunlight reflected from the shiny surface of the carrier as it tumbled over and over.
John Hodges tells us that the carrier was somewhat ahead of the satellite which it had put into orbit. The satellite could not be seen with the unaided eye but could be made out with binoculars. The satellite weighed 2,925 pounds and had an orbit varying from 150 to 1,170 miles from the earth's surface. It may stay in orbit for about six months.

\section{What Can The Astronomer and Archaeologist Tell Us About Climate? \\ by John Hodges, Regina}

Archaeology and astronomy are both contributing information about the earth's climate. This is part of the story of how that interesting and important relationship developed. It could possibly affect you and it does most likely affect the abundance of wildlife.

Some of this story was written as early as 1923 by Dr. A. E. Douglass, who was an astronomer. He was then director of Steward Observatory, University of Arizona, and yet he was invited to study trees. Dr. Douglass received this unusual invitation not because he wanted to be a biologist but because he was the world's 
leading scientist studying sunspots. It had been known for some time that sunspots waxed and waned in an eleven-year cycle. Dr. Douglass welcomed the opportunity to investigate the rings in trees to see if an elevenyear cycle was recorded in their growth. In brief, did solar changes affect our weather?

$\mathrm{He}$ chose the Arizona pine for study, for here was a tree that reliably grew one ring for each growing season; thin if during drought, thick if rainfall had been plentiful. He used cores taken from living trees and also from the beams the Indians of the southwest used in constructing the roofs of their homes. By matching the spaces between rings of growth he succeeded in determining the dates when the beams had been cut. An astronomer had made a remarkable contribution to archaeology. He had found an unusual but sure method of dating the pueblos of the southwest.

Dr. Douglas: found that a cycle did exist in the tree rings. His record was complete from 700 A.D. to the present. Only one period of rings, for 75 years beginning at 1650 , did not appear to have any cycles.

Dr. E. Walter Maunder, an eminent English astronomer, wrote Dr. Douglass that a search of early observatory records revealed an unusual fact. No record existed of sunspots being observed from 1645 to 1715 . He stated that if the tree rings being studied by Dr. Douglass failed to reveal this gap, then the cycles in the tree rings must have some other cause. He did not then know of the gap in the cycle in the annual rings of the Arizona pine. This confirms the idea that sunspots affect the growth of trees because of variation in weather following the sunspots cycles.

The foregoing is not the only reason to suspect that climatic changes, and astronomy and archaeology are intimately related. Saskatchewan has recently contributed information from its sands and clays.

In 1954, Mr. Boyd Wettlaufer, archaeologist and geologist, conducted an excavaltion at Mortlach. Great importance was placed on the type of material in which each artifact was found. His report revealed that climate had played an important part in depositing the layers of material in the Besant Valley. Mortlach is a stratified site with each layer lying relatively undisturbed on top of an older layer. It proved to be a book holding between its covers the story of past climatic conditions as related to the occupational levels of peoples who lived there when they could.

Saskatchewan is rich in sites once occupied by man. They await investigaltion. An intensive archaeological programme in Saskatchewan might do much to explain man's past and predict his future. Already sites have told us that man lived here 5,000 years ago. Unlike the archaeologist's files, the astronomer's only go back a few hundred years. They show us that the sun is responsible for influencing our climate. Only study will reveal how and why. There is a fascinating story to be written, that of the battle of man and climate in which the sun plays a determining role.

Ft:

\section{S.N.H.S. CHRISTMAS CARDS AND HASTI-NOTES}

Although it is late in the season, we remind you again of the S.N.H.S. Christmas cards and hasti-notes. The Christmas cards are available in one design only - Bcggy Creek winter scene (Kodachrome by Richard Fyfe); the hasti-notes in two designs
- either the Boggy Creek winter scene or the Western Red Lily (Kodachrome by Fred Robinson). Christas and hasti-notes are both priced at $\$ 1.25$ per dozen. Order from Margaret Belcher, Blue Jay, Regina College, Regina.

\section{CHRISTMAS GIFT SUGGESTION}

For those wishing to send a Christmas gift subscription to the Blue Jay we make the following offer. We shall mail a copy of the December issue now, with an S.N.H.S. card announcing the gift, and four regular issues will follow in 1959. To cover the five issues and the sending of the card, the gift subscription rate will be $\$ 1.25$. Write at once to E. L. Fox, 1053 Gladmer Park, Regina. 